\title{
Potassium tert-Butoxide Promoted Synthesis of 4,5-Diaryl-2H- 1,2,3-triazoles from Tosylhydrazones and Nitriles
}

\author{
Shanguang Qiu \\ Yuxue Chen \\ Xinming Song \\ Li Liu \\ Xi Liu \\ Luyong $\mathrm{Wu}^{*}$
}

Key Laboratory of Tropical Medicinal Resource Chemistry of

Ministry of Education, Hainan Normal University, No. 99,

Longkun South Road, Haikou 571158, P. R. of China

wuluyong@hainnu.edu.cn

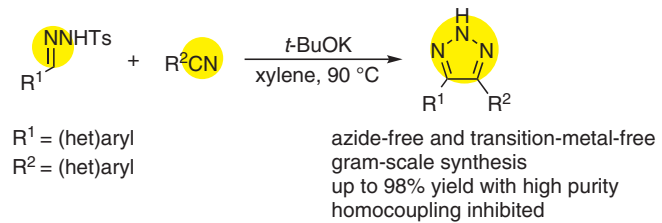

Generally, 4,5-diaryl- $\mathrm{NH}$-1,2,3-triazoles have been synthesized by $[3+2]$-cycloaddition of diarylalkynes with trimethylsilyl azide ${ }^{7}$ or sodium azide ${ }^{8}$ (Scheme $1 \mathrm{a}$ ). Because of the potential explosivity and toxicity of azides, ${ }^{9}$ the concept of azide-free synthesis has been widely adopted in the synthesis of 1,2,3-triazoles. ${ }^{10}$ This progress has also influenced the synthesis of $\mathrm{NH}$-1,2,3-triazoles. ${ }^{11}$ It is therefore imperative to explore azide-free protocols for the synthesis of 4,5-diaryl-1,2,3-triazoles. In 1988, Grundon and Khan reported that the reactions of aryldiazomethanes with arylaldehyde azines or aryl nitriles gave the corresponding 4,5diaryl- $\mathrm{NH}-1,2,3$-triazoles in moderate yields (Scheme 1b). ${ }^{12}$ Perhaps, the instability, hazardous nature, and difficulty in handling of diazo compounds has restricted the use of this cycloaddition reaction and, consequently, this work is rarely mentioned in the literature on 1,2,3-triazoles.

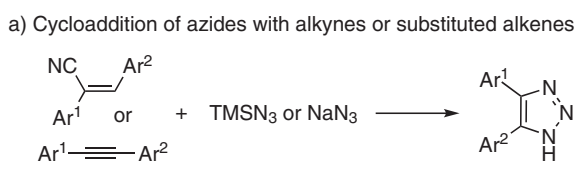

$$
\text { b) Cyclization of aryldiazomethanes with nitriles or azines }
$$

c) Homo- and heterocoupling of $\mathrm{N}$-tosylhydrazones

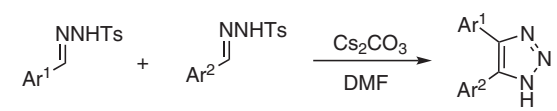

d) This work: intermolecular reaction of $N$-tosylhydrazones with nitriles

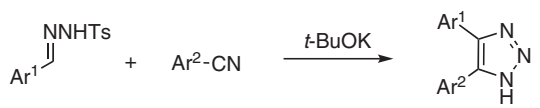

Scheme 1 Synthetic approaches to 4,5-diaryl-NH-1,2,3-triazoles 
In recent decades, tosylhydrazones have attracted intense interest from the organic-synthesis community, ${ }^{4 \mathrm{~d}, 5 \mathrm{~b}, 13}$ and they have been widely used in many reactions as excellent and safe precursors of diazo compounds. ${ }^{14}$ Furthermore, the use of tosylhydrazones as versatile synthons has been explored in many novel reactions to afford various heterocycles, including 1,2,3-triazoles. ${ }^{15}$ Recently, the groups of Sakač and Mani reported a synthesis of $\mathrm{NH}-1,2,3-$ triazoles through 1,3-dipolar cycloadditions of diazo compounds generated in situ from tosylhydrazones. ${ }^{16}$ Obviously, the preparation of 4,5-diaryl- $\mathrm{NH}-1,2,3$-triazoles by 1,3 dipolar cycloadditions of nitriles with diazo compounds generated in situ from tosylhydrazones would constitute an elegant protocol.

In 2017, the group of Maity and Manna described regioselective syntheses of 1,2,3-triazoles and pyrazoles from tosylhydrazones. ${ }^{17}$ They succeeded in synthesizing 4,5-diaryl- $\mathrm{NH}-1,2,3$-triazoles in moderate to good yields by coupling tosylhydrazones. They also showed that the electronic nature of tosylhydrazone influenced the coupling process. As the results, when cross-couplings of different tosylhydrazones were carried out, the corresponding homocoupled $\mathrm{NH}$-triazoles were obtained as byproducts and reduced the purity of the desired products. The authors also explored the intermolecular reactions of tosylhydrazones with nitriles to provide two 4,5-diaryl- $\mathrm{NH}-1,2,3$-triazoles, ${ }^{17}$ in which homocoupling of the tosylhydrazones similarly decreased the yields and the purities of the products (Scheme 1c). ${ }^{17}$ The challenge therefore remained of inhibiting the homocoupling cyclization of tosylhydrazones to provide 4,5-diaryl- $\mathrm{NH}$-1,2,3-triazoles with high efficiency and high purity. Because of our continuing interest in 1,2,3-triazoles, ${ }^{18}$ we decide to explore further the azide-free reaction of tosylhydrazones with nitriles (Scheme 1d).

Initially, we chose benzaldehyde tosylhydrazone (1a) and benzonitrile (2a) as model substrates for the optimization of the reaction conditions (Table 1 ). $\mathrm{K}_{2} \mathrm{CO}_{3}$, generally

Table 1 Optimization of the Intermolecular Cyclization ${ }^{a}$

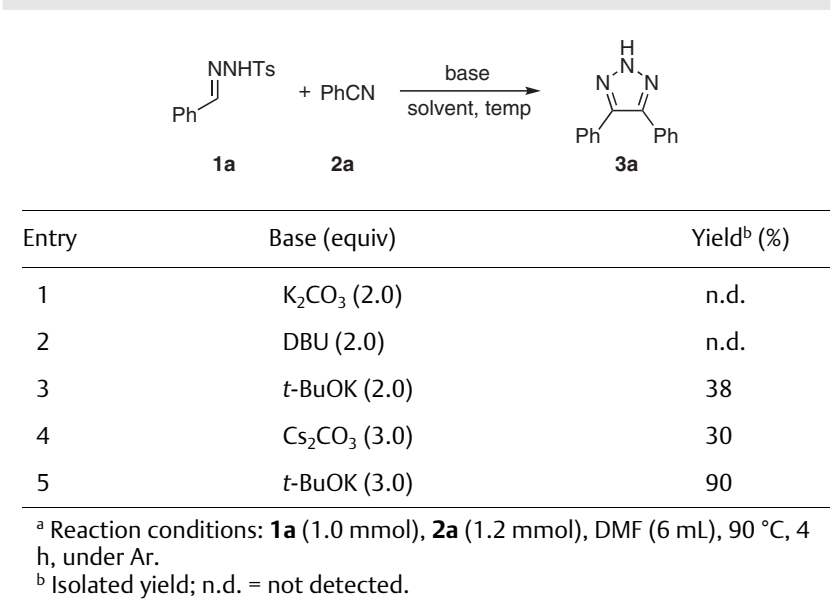

suitable as a base in intramolecular cycloadditions, ${ }^{16}$ did not facilitate the intermolecular reaction. However, when 2.0 equivalents of $t$-BuOK were used as the base, the desired product was isolated in $38 \%$ yield, along with benzaldehyde azine $^{19}$ as a byproduct in a yield of $35 \%$ (entry 3 ). Encouraged by this result, and with the aim of restraining the formation of the benzaldehyde azine byproduct, we increased the amount of $t$-BuOK to 3.0 equivalents, and this gave the desired product in an excellent yield of $90 \% . \mathrm{Cs}_{2} \mathrm{CO}_{3}$ as a base gave a lower yield of $30 \%$. When we screened other
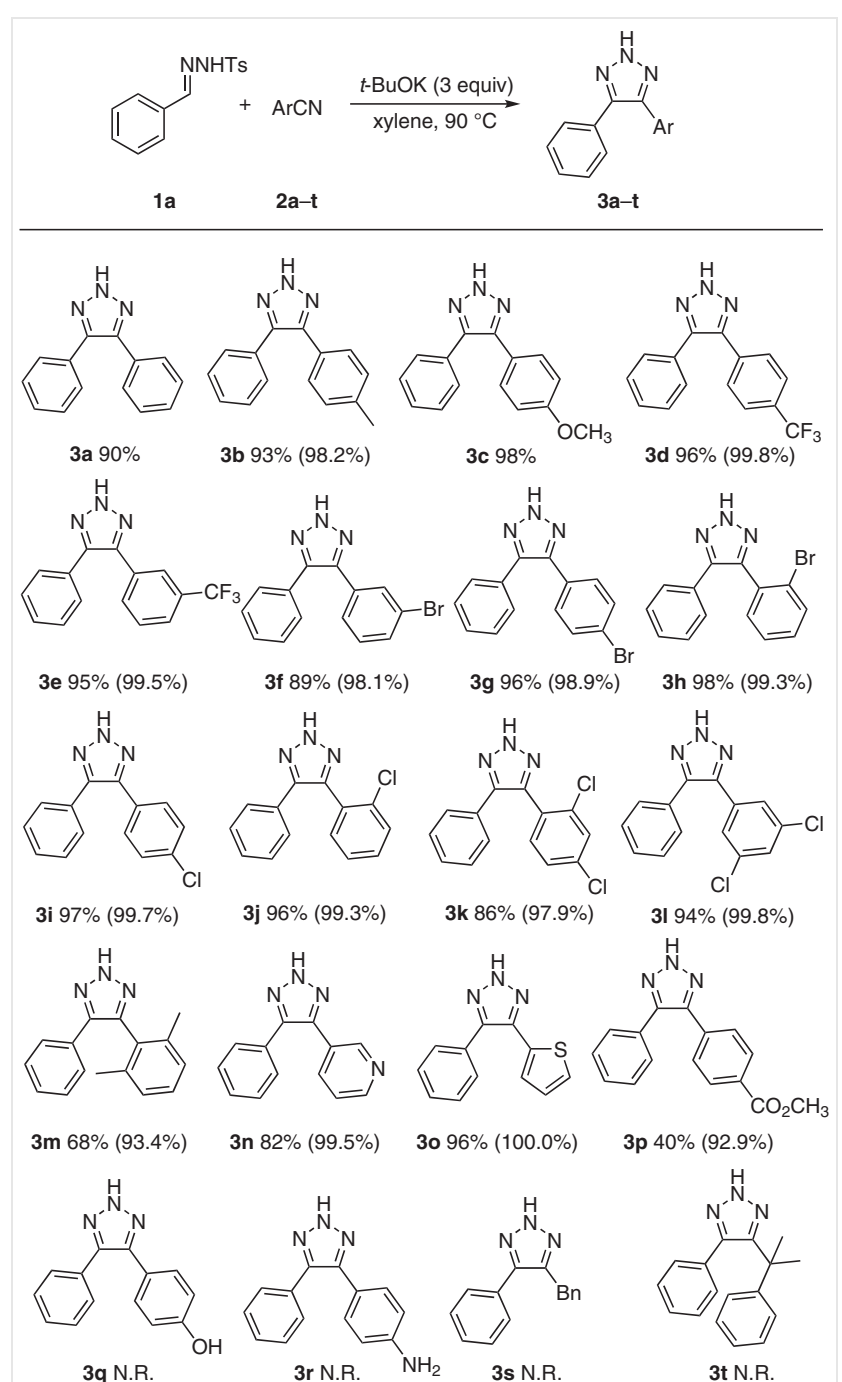

Scheme 2 Reactions of benzaldehyde tosylhydrazone (1a) with various nitriles under the optimized conditions. Reaction conditions: 1a (1.0 $\mathrm{mmol}), 2$ (1.2 mmol), xylene $(6 \mathrm{~mL}), 90^{\circ} \mathrm{C}, 4 \mathrm{~h}$. The yields of the crosscoupling products were calculated from the combined isolated yields of the mixtures of the homocoupled 1,2,3-triazole and the cross-coupled 1,2,3-triazole. The figures in parentheses are the purities of the crosscoupled 1,2,3-triazole, determined by reverse-phase HPLC. N.R. = No reaction. 
bases (see Supporting Information), we found that the use of $t$-BuOK as a strong base is critical in improving the efficiency of this intermolecular reaction.

Having increased the efficiency of the intermolecular reaction of the tosylhydrazone and nitrile, we turned our interest to the inhibition of the homocoupling of the tosylhydrazone. When the reaction of benzaldehyde tosylhydrazone (1a) and 4-methylbenzonitrile $\mathbf{2 b}$ was carried out, the 4,5-diphenyl-2H-1,2,3-triazole (3a) homocoupling byproduct could not be separated from the desired product $\mathbf{3 b}$ by flash column chromatography on silica gel. When DMF was used as the solvent, the isolated product contained $6.1 \%$ of homocoupling product. When toluene or xylene was used, however, the proportion of $\mathbf{3 a}$ (as determined by HPLC) was significantly reduced, and xylene was found to give the best result in terms of the yield and the selectivity. We surmised that, in comparison with $\mathrm{Cs}_{2} \mathrm{CO}_{3}$, the greater basicity of $t$ $\mathrm{BuOK}$ is a critical factor in relation to the deprotonation of the tosylhydrazone to transfer anions or diazo compounds, thereby markedly inhibiting the homocoupling of the tosylhydrazone. Therefore the optimal reaction conditions are: tosylhydrazone (1.0 mmol), nitrile (1.2 mmol), $t$-BuOK (3.0 $\mathrm{mmol}$ ) for four hours at $90{ }^{\circ} \mathrm{C}$ under an $\mathrm{Ar}$ atmosphere.
Table 2 Optimization of the Inhibition of Homocoupling of the N-Tosylhydrazone

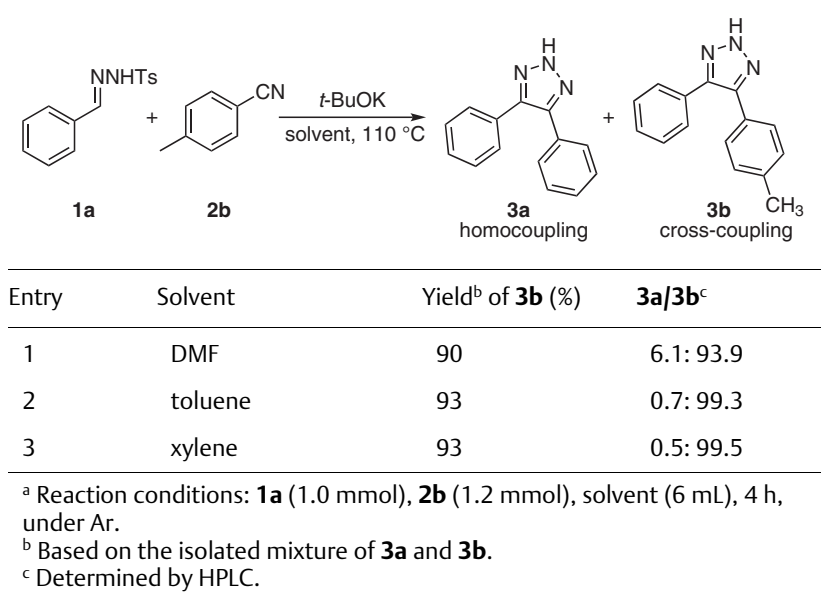

\begin{tabular}{llll}
\hline Entry & Solvent & Yield $^{\mathrm{b}}$ of $\mathbf{3 b}(\%)$ & $\mathbf{3} \mathbf{a} / \mathbf{3 b}^{\mathrm{c}}$ \\
\hline 1 & DMF & 90 & $6.1: 93.9$ \\
2 & toluene & 93 & $0.7: 99.3$ \\
3 & xylene & 93 & $0.5: 99.5$ \\
\hline
\end{tabular}

With these optimized conditions in hand, we extended the scope of the method to the reactions of 1a with various nitriles $\mathbf{2}$ (Scheme 2). The intermolecular cyclization reaction was found to tolerate various substituents on the aryl nitrile 2, and gave the desired products $\mathbf{3 a - 0}$ in good to ex-

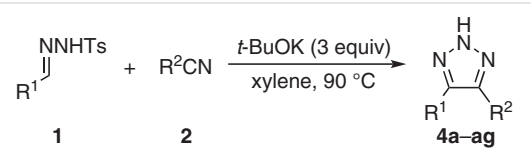

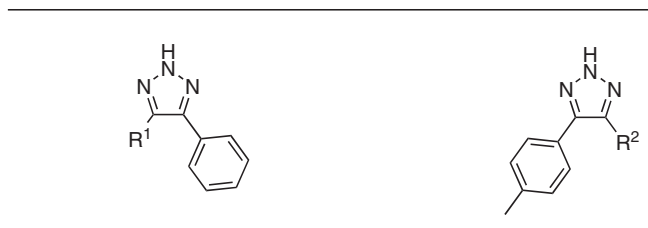

$\mathrm{R}^{1}=p-\mathrm{CH}_{3} \mathrm{C}_{6} \mathrm{H}_{4}, 4 \mathrm{a} 92 \%$ (98.5\%) $\mathrm{R}^{1}=p-\mathrm{CH}_{3} \mathrm{OC}_{6} \mathrm{H}_{4}, \mathbf{4 b} 91 \%$

$\mathrm{R}^{1}=p-\mathrm{CF}_{3} \mathrm{C}_{6} \mathrm{H}_{4}, 4 \mathrm{c} 90 \%(100.0 \%)$

$\mathrm{R}^{1}=p-\mathrm{ClC}_{6} \mathrm{H}_{4}, 4 \mathrm{~d} 98 \%(97.2 \%)$
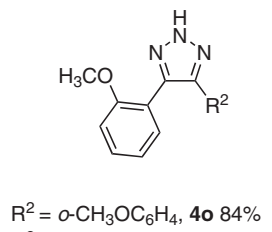
$\mathrm{R}^{2}=p-\mathrm{CIC}_{6} \mathrm{H}_{4}, 4 \mathrm{p} 82 \%$

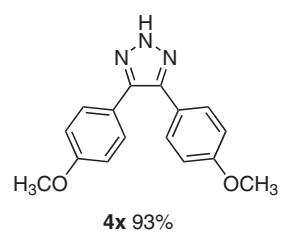

$\mathrm{R}^{2}=p-\mathrm{CH}_{3} \mathrm{C}_{6} \mathrm{H}_{4}, 4 \mathrm{e} 77 \%$ $\mathrm{R}^{2}=m-\mathrm{CH}_{3} \mathrm{C}_{6} \mathrm{H}_{4}, \mathbf{4 f} 98 \%(100.0 \%)$ $\mathrm{R}^{2}=0-\mathrm{CH}_{3} \mathrm{C}_{6} \mathrm{H}_{4}, \mathbf{4 g} 97 \%$ (99.3\%) $\mathrm{R}^{2}=p-\mathrm{ClC}_{6} \mathrm{H}_{4}, 4 \mathrm{~h} 98 \%$ (99.4\%)

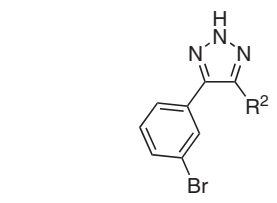

$\mathrm{R}^{2}=m-\mathrm{BrC}_{6} \mathrm{H}_{4}, 4 \mathbf{q} 90 \%$ $\mathrm{R}^{2}=p-\mathrm{CH}_{3} \mathrm{C}_{6} \mathrm{H}_{4}, 4 \mathrm{r} 95 \%(97.8 \%)$

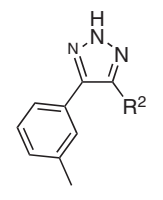

$\mathrm{R}^{2}=m-\mathrm{CH}_{3} \mathrm{C}_{6} \mathrm{H}_{4}, 4 \mathbf{i} 98 \%$

$\mathrm{R}^{2}=0-\mathrm{CH}_{3} \mathrm{C}_{6} \mathrm{H}_{4}, 4 \mathrm{j} 96 \%(97.8 \%)$ $R^{2}=3,5-\mathrm{diClC}_{6} \mathrm{H}_{3}, \mathbf{4 k} 93 \%$ (100.0\%)

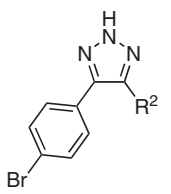

$\mathrm{R}^{2}=p-\mathrm{BrC}_{6} \mathrm{H}_{4}, 4 \mathbf{s} 97 \%$

$\mathrm{R}^{2}=p-\mathrm{CH}_{3} \mathrm{C}_{6} \mathrm{H}_{4}, 4 \mathrm{t} 98 \%(97.4 \%)$

$\mathrm{R}^{2}=0-\mathrm{BrC}_{6} \mathrm{H}_{4}, 4 \mathrm{u} 67 \%$ (98.5\%)

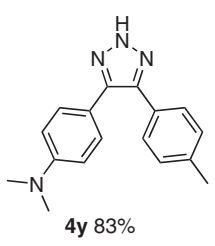

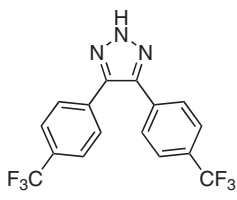

$4 z 82 \%$

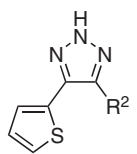

$\mathrm{R}^{2}=2$-thienyl, 4 aa $76 \%$

$\mathrm{R}^{2}=p-\mathrm{CH}_{3} \mathrm{C}_{6} \mathrm{H}_{4}, 4 \mathrm{ab} 63 \%$ (98.6\%)

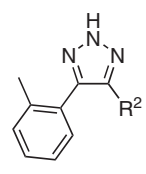

$\mathrm{R}^{2}=0-\mathrm{CH}_{3} \mathrm{C}_{6} \mathrm{H}_{4}, 4 \mathrm{I} 82 \%$ $\mathrm{R}^{2}=p-\mathrm{CH}_{3} \mathrm{C}_{6} \mathrm{H}_{4}, 4 \mathrm{~m} 97 \%$ (98.7\%) $\mathrm{R}^{2}=p-\mathrm{CH}_{3} \mathrm{OC}_{6} \mathrm{H}_{4}, 4 \mathrm{n} 87 \%$

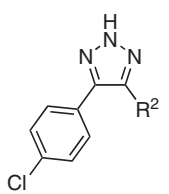

$\mathrm{R}^{2}=p-\mathrm{ClC}_{6} \mathrm{H}_{4}, 4 \mathbf{v} 96 \%$

$\mathrm{R}^{2}=0-\mathrm{CH}_{3} \mathrm{OC}_{6} \mathrm{H}_{4}, 4 \mathrm{w} 94 \%$ (100.0\%)

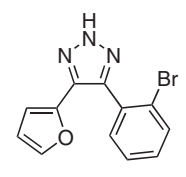

4 ac $87 \%$

Scheme 3 Reaction scope of tosylhydrazones 1 with nitriles 2 under the optimized conditions. Reaction conditions: $1 \mathrm{a}(1.0 \mathrm{mmol}), \mathbf{2}(1.2 \mathrm{mmol})$, xylene $(6 \mathrm{~mL}), 90^{\circ} \mathrm{C}, 4 \mathrm{~h}$, under Ar. The yields of the cross-coupling products were calculated from the combined isolated yields of the mixtures of the homocoupled 1,2,3-triazole and the cross-coupled 1,2,3-triazole. The figures in parentheses are the purities of the cross-coupled 1,2,3-triazole, determined by reverse-phase HPLC. 
cellent yields of 68-98\%; however, the methoxycarbonylsubstituted product $3 p$ was obtained in only $40 \%$ yield. Only small amounts of the corresponding homocoupling products of the tosylhydrazones were formed, and the crosscoupling products of the tosylhydrazone with the nitrile were formed in high ratios. The yields were little affected by the presence of electron-withdrawing or electron-donating groups on the nitriles. Moreover, the presence of steric hindrance at the ortho-position had little effect on the yields in this transformation (3h, $\mathbf{3 j}$, and $\mathbf{3 k}$ ). However, an aryl nitrile bearing two methyl groups at the two ortho-positions gave the corresponding 1,2,3-triazole $\mathbf{3 m}$ in a lower yield and a lower cross-coupling ratio. Heterocyclic aryl nitriles also worked well under optimized conditions, and gave good yields of corresponding 1,2,3-triazoles $\mathbf{3 n}$ and $\mathbf{3 o}$ with a high cross-coupling ratio. Unfortunately, when a hydroxy or amino group was present in the benzonitrile, the desired product was not obtained and the unreacted nitrile was recovered by column chromatography (3q, 3r). Nonaromatic nitriles $\mathbf{2 s}$ and $\mathbf{2 t}$ also failed to give the desired products 3s and 3t. When phenylacetonitrile was used, the benzaldehyde azine was isolated.

To further expand the scope of this reaction, a series of tosylhydrazones were explored in reactions with various nitriles under the optimized conditions (Scheme 3). Generally, the corresponding 1,2,3-triazoles were obtained in good to excellent yields with high purities. The cyclization was highly tolerant of various functional groups on the benzene rings. When electron-rich or electron-deficient phenyl tosylhydrazones reacted with benzonitrile, the 1,2,3-triazoles 4a-d were obtained in excellent yields and high purities. The reaction also permitted the use of other substituted benzaldehyde tosylhydrazones with substituted benzonitriles (4e-z). Additionally, hetaryl aldehyde tosylhydrazones were also well tolerated, affording corresponding 1,2,3-triazoles 4aa-ac in good yields.

To demonstrate the synthetic utility of the reaction, we performed a gram-scale reaction (Scheme 4). When 1a and 2b were used as substrates, the corresponding product $\mathbf{3 b}$ was isolated by column chromatography in $85 \%$ yield and a purity of $98.4 \%$

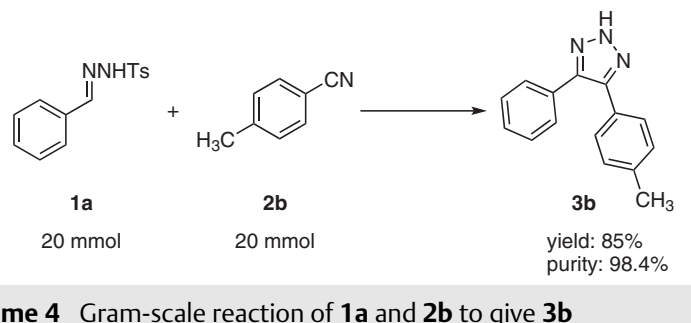

Scheme 4 Gram-scale reaction of $\mathbf{1} \mathbf{a}$ and $\mathbf{2} \mathbf{b}$ to give $\mathbf{3 b}$

In summary, an intermolecular reaction of tosylhydrazones with nitriles is described. ${ }^{20}$ This reaction proceeded smoothly when promoted by potassium tert-butoxide in xylene; these conditions were beneficial to intermolecular cyclization and inhibited the homocoupling of the tosylhydrazone. The reaction provides an efficient and convenient method for the synthesis of $\mathrm{NH}$-1,2,3-triazoles, and a wide range of 4,5-diaryl- $2 \mathrm{H}-1,2,3$-triazoles were obtained in good to excellent yields.

\section{Funding Information}

This work was supported by the Natural Science Foundation of Hainan Province (219MS044) and the National Natural Science Foundation of China (NSFC-21562019).

\section{Acknowledgment}

We are grateful to our colleagues in the Centre for Instrumental Analysis for providing services.

\section{Supporting Information}

Supporting information for this article is available online at https://doi.org/10.1055/s-0040-1707321.

\section{References and Notes}

(1) (a) Weide, T.; Saldanha, S. A.; Minond, D.; Spicer, T. P.; Fotsing, J. R.; Spaargaren, M.; Frère, J.-M.; Bebrone, C.; Sharpless, K. B.; Hodder, P. S.; Fokin, V. V. ACS Med. Chem. Lett. 2010, 1, 150. (b) Madadi, N. R.; Penthala, N. R.; Howk, K.; Ketkar, A.; Eoff, R. L.; Borrelli, M. J.; Crooks, P. A. Eur. J. Med. Chem. 2015, 103, 123. (c) Cheng, Z.-Y.; Li, W.-J.; He, F.; Zhou, J.-M.; Zhu, X.-F. Bioorg. Med. Chem. 2007, 15, 1533. (d) Röhrig, U. F.; Majjigapu, S. R.; Grosdidier, A.; Bron, S.; Stroobant, V.; Pilotte, L.; Colau, D.; Vogel, P.; Van den Eynde, B. J.; Zoete, V.; Michielin, O. J. Med. Chem. 2012, 55, 5270. (e) Röhrig, U. F.; Awad, L.; Grosdidier, A.; Larrieu, P.; Stroobant, V.; Colau, D.; Cerundolo, V.; Simpson, A. J. G.; Vogel, P.; Van den Eynde, B. J.; Zoete, V.; Michielin, O. J. Med. Chem. 2010, 53, 1172. (f) Penthala, N. R.; Madhukuri, L.; Thakkar, S.; Madadi, N. R.; Lamture, G.; Eoff, R. L.; Crooks, P. A. Med. Chem. Commun. 2015, 6, 1535.

(2) (a) Zhang, W.; Kuang, C.; Yang, Q. Youji Huaxue 2011, 31, 54. (b) Tomé, A. C. In Science of Synthesis, Vol. 13; Storr, R. C.; Gilchrist, T. L., Ed.; Thieme: Stuttgart, 2004, Chap. 13, 415. (c) Krivopalov, V. P.; Shkurko, O. P. Russ. Chem. Rev. 2005, 74, 339.

(3) (a) Rostovtsev, V. V.; Green, L. G.; Fokin, V. V.; Sharpless, K. B. Angew. Chem. Int. Ed. 2002, 41, 2596. (b) Tornøe, C. W.; Christensen, C.; Meldal, M. J. Org. Chem. 2002, 67, 3057.

(4) (a) Quan, X.-J.; Ren, Z.-H.; Wang, Y.-Y.; Guan, Z.-H. Org. Lett. 2014, 16, 5728; corrigendum: Org. Lett. 2015, 17, 393. (b) Li, J.; Wang, D.; Zhang, Y.; Li, J.; Chen, B. Org. Lett. 2009, 11, 3024. (c) Roshandel, S.; Suri, S. C.; Marcischak, J. C.; Rasula, G.; Prakash, G. K. S. Green Chem. 2018, 20, 3700. (d) Gao, Y.; Lam, Y. Org. Lett. 2006, 8, 3283. (e) Augustine, J. K.; Boodappa, C.; Venkatachaliah, S. Org. Biomol. Chem. 2014, 12, 2280.

(5) (a) Wu, G.-L.; Wu, Q.-P. Synthesis 2018, 50, 2768. (b) Wu, G.-L.; Wu, Q.-P. Adv. Synth. Catal. 2018, 360, 1949. (c) Xu, C.; Jiang, S.F.; Wu, Y.-D.; Jia, F.-C.; Wu, A.-X. J. Org. Chem. 2018, 83, 14802. 
(6) (a) Loren, J. C.; Sharpless, K. B. Synthesis 2005, 1514. (b) Barluenga, J.; Valdés, C.; Beltrán, G.; Escribano, M.; Aznar, F. Angew. Chem. Int. Ed. 2006, 45, 6893. (c) Zhang, H.; Tanimoto, H.; Morimoto, T.; Nishiyama, Y.; Kakiuchi, K. Org. Lett. 2013, 15, 5222. (d) Ramachary, D. B.; Shashank, A. B. Chem. Eur. J. 2013, 19, 13175. (e) Liu, Y.; Yan, W.; Chen, Y.; Petersen, J. L.; Shi, X. Org. Lett. 2008, 10, 5389. (f) Chai, H.; Guo, R.; Yin, W.; Cheng, L.; Liu, R.; Chu, C. ACS Comb. Sci. 2015, 17, 147. (g) Zhang, W.; Kuang, C.; Yang, Q. Synthesis 2010, 283.

(7) Kim, D.-K.; Kima, J.; Park, H.-J. Bioorg. Med. Chem. Lett. 2004, 14, 2401.

(8) (a) Tsai, C.-W.; Yang, S.-C.; Liu, Y.-M.; Wu, M.-J. Tetrahedron 2009, 65, 8367. (b) Madadi, N. R.; Penthala, N. R.; Song, L.; Hendrickson, H. P.; Crooks, P. A. Tetrahedron Lett. 2014, 55, 4207.

(9) (a) Chang, S.; Lamm, S. H. Int. J. Toxicol 2003, 22, 175. (b) Bräse, S.; Banert, K. Organic Azides: Syntheses and Applications; Wiley: Chichester, 2010.

(10) (a) van Berkel, S. S.; Brauch, S.; Gabriel, L.; Henze, M.; Stark, S.; Vasilev, D.; Wessjohann, L. A.; Abbas, M.; Westermann, B. Angew. Chem. Int. Ed. 2012, 51, 5343. (b) Wan, J.-P.; Hu, D.; Liu, Y.; Sheng, S. ChemCatChem 2015, 7, 901. (c) Chen, Z.; Yan, Q.; Liu, Z.; Xu, Y.; Zhang, Y. Angew. Chem. Int. Ed. 2013, 52, 13324. (d) Cai, Z.-J.; Lu, X.-M.; Zi, Y.; Yang, C.; Shen, L.-J.; Li, J.; Wang, S.Y.; Ji, S.-J. Org. Lett. 2014, 16, 5108. (e) Liu, H.-N.; Cao, H.-Q.; Cheung, C.-W.; Ma, J.-A. Org. Lett. 2020, 22, 1396. (f) Guru, M. M.; Punniyamurthy, T. J. Org. Chem. 2012, 77, 5063. (g) Gu, J.; Fang, Z.; Yang, Z.; Li, X.; Zhu, N.; Wan, L.; Wei, P.; Guo, K. RSC Adv. 2016, 6, 89073. (h) Chen, Z.; Yan, Q.; Liu, Z.; Zhang, Y. Chem. Eur.J. 2014, 20, 17635. (i) Wang, S.; Yang, L.-J.; Zeng, J.-L.; Zheng, Y.; Ma, J.-A. Org. Chem. Front. 2015, 2, 1468. (j) Ahamad, S.; Kant, R.; Mohanan, K. Org. Lett. 2016, 18, 280.

(11) He, Y.; Sun, E.; Zhao, Y.; Hai, L.; Wu, Y. Tetrahedron Lett. 2014, $55,111$.

(12) Grundon, M. F.; Khan, E. A. J. Chem. Soc., Perkin Trans. 1 1988, 2917.

(13) (a) Li, D.; Liu, L.; Tian, Y.; Ai, Y.; Tang, Z.; Sun, H.-b.; Zhang, G. Tetrahedron 2017, 73, 3959. (b) Hu, L.; Mück-Lichtenfeld, C.; Wang, T.; He, G.; Gao, M.; Zhao, J. Chem. Eur. J. 2016, 22, 911. (c) Hu, Q.; Liu, Y.; Deng, X.; Li, Y.; Chen, Y. Adv. Synth. Catal. 2016, 358, 1689. (d) Jin, T.; Kamijo, S.; Yamamoto, Y. Eur. J. Org. Chem. 2004, 2004, 3789.

(14) Shu, W.-M.; Zhang, X.-F.; Zhang, X.-X.; Li, M.; Wang, A.-J.; Wu, A.-X. J. Org. Chem. 2019, 84, 14919.

(15) (a) Guru, M. M.; De, S.; Dutta, S.; Koley, D.; Maji, B. Chem. Sci. 2019, 10, 7964. (b) Shen, X.; Gu, N.; Liu, P.; Ma, X.; Xie, J.; Liu, Y.; He, L.; Dai, B. RSC Adv. 2015, 5, 63726.

(16) (a) Sakač, M. N.; Gaković, A. R.; Csanádi, J. J.; Djurendić, E. A.; Klisurić, O.; Kojić, V.; Bogdanović, G.; Gaši, K. M. P. Tetrahedron Lett. 2009, 50, 4107. (b) Mani, N. S.; Fitzgerald, A. E. J. Org. Chem. 2014, 79, 8889.

(17) Panda, S.; Maity, P.; Manna, D. Org. Lett. 2017, 19, 1534.

(18) (a) Wu, L.-Y.; Xie, Y.-X.; Chen, Z.-S.; Niu, Y.-N.; Liang, Y.-M. Synlett 2009, 1453. (b) Wu, L.; Chen, Y.; Tang, M.; Song, X.; Chen, G.; Song, X.; Lin, Q. Synlett 2012, 23, 1529. (c) Wu, L.; Chen, Y.; Luo, J.; Sun, Q.; Peng, M.; Lin, Q. Tetrahedron Lett. 2014, 55, 3847. (d) Wu, L.; Guo, S.; Wang, X.; Guo, Z.; Yao, G.; Lin, Q.; Wu, M. Tetrahedron Lett. 2015, 56, 2145. (e) Wu, L.; Wang, X.; Chen, Y.; Huang, Q.; Lin, Q.; Wu, M. Synlett 2016, 27, 437. (f) Wu, L.; Chen, Y.; He, W.; An, M.; Yan, G.; Fu, Q.; Chen, M. CN 108794412, 2018.

(19) Sha, Q.; Wei, Y. Tetrahedron 2013, 69, 3829.

(20) 4,5-Diaryl-2H-1,2,3-triazoles 3a-t, 4a-ag; General Procedure A mixture of the appropriate tosylhydrazone $1(1.0 \mathrm{mmol})$, nitrile $2(1.2 \mathrm{mmol})$, and $t$-BuOK $(3.0 \mathrm{mmol})$ in xylene $(6 \mathrm{~mL})$ was stirred at $90{ }^{\circ} \mathrm{C}$ for $4 \mathrm{~h}$ under Ar. The mixture was then cooled to r.t. and diluted with EtOAc $(40 \mathrm{~mL})$. The organic layer was washed with water $(3 \times 40 \mathrm{~mL})$ and brine $(30 \mathrm{~mL})$, then dried $\left(\mathrm{Na}_{2} \mathrm{SO}_{4}\right)$ and filtered. The filtrate was concentrated in vacuum, and the crude product was purified by column chromatography (silica gel, PE-EtOAc).

4,5-Bis(4-methoxyphenyl)-2H-1,2,3-triazole (4x)

White solid; yield: $261.3 \mathrm{mg}$ (93\%); $\mathrm{mp} 121.9-124.9{ }^{\circ} \mathrm{C} .{ }^{1} \mathrm{H}$ NMR $\left(400 \mathrm{MHz}, \mathrm{CDCl}_{3}\right): \delta=7.41(\mathrm{~d}, J=8.8 \mathrm{~Hz}, 4 \mathrm{H}), 6.79(\mathrm{~d}, J=8.9 \mathrm{~Hz}$, $4 \mathrm{H}), 3.74(\mathrm{~s}, 6 \mathrm{H}) .{ }^{13} \mathrm{C}$ NMR $\left(100 \mathrm{MHz}, \mathrm{CDCl}_{3}\right): \delta=159.5,140.6$, 129.3, 122.2, 113.9, 55.0. 